\title{
Bis-dimethylaminobenzaldehyde Schiff-Base Cobalt(II) Complex as a Neutral Carrier for a Highly Selective Iodide Electrode
}

\author{
Jianyuan DaI, Yaqin ChaI, Ruo Yuan, ${ }^{\dagger}$ Xia Zhong, Yan LiU, and Dianping TANG \\ Chongqing Key Laboratory of Analytical Chemistry, Southwest China Normal University, \\ Chongqing 400715, P. R. China
}

\begin{abstract}
A new solvent polymeric membrane electrode based on $N, N^{\prime}$-bis-(dimethylaminobenzaldehyde)-glycine cobalt(II) [Co(II)-BDMABG] as a neutral carrier is described, which displays a preferential potentiometric response to iodide ion and an anti-Hofmeister selectivity sequence in the following order: $\mathrm{I}^{-}>\mathrm{ClO}_{4}^{-}>\mathrm{Sal}^{-}>\mathrm{SCN}^{-}>\mathrm{NO}_{2}^{-}>\mathrm{Br}^{-}>\mathrm{NO}_{3}^{-}>\mathrm{Cl}^{-}>$ $\mathrm{SO}_{3}{ }^{2-}>\mathrm{SO}_{4}{ }^{2-}$. The electrode exhibits a near-Nernstian potential linear range of $9.0 \times 10^{-7}-1.0 \times 10^{-1} \mathrm{M}$ with a detection limit of $6.8 \times 10^{-7} \mathrm{M}$ and a slope of $-53.0 \mathrm{mV} /$ decade in $\mathrm{pH} 2.0$ of a phosphate buffer solution at $20^{\circ} \mathrm{C}$. The response mechanism is discussed in view of the A.C. impedance technique and the UV spectroscopy technique. The electrode was successfully applied to the determination of iodide in Jialing River and Spring in Jinyun Mountains with satisfactory results.
\end{abstract}

(Received July 5, 2004; Accepted September 7, 2004)

\section{Introduction}

A study on anti-Hofmeister sensing materials with high selectivity for given anions is an expeditiously expanding domain in the field of chemical sensors. Membranes based on ion exchangers, such as lipophilic quaternary ammonium or phosphonium salts, display the classical Hofmeister behavior, in which the membrane selectivity is controlled by the free energy of hydration of ions involved with a selectivity sequence: $\mathrm{ClO}_{4}^{-}$ $>\mathrm{SCN}^{-}>\mathrm{I}^{-} \approx \mathrm{Sal}^{-}>\mathrm{NO}_{3}{ }^{-}>\mathrm{Br}^{-}>\mathrm{NO}_{2}{ }^{-}>\mathrm{Cl}^{-}>\mathrm{SO}_{4}{ }^{2-} .1,2$ Recently, electrodes using plasticized poly(vinyl chloride) (PVC) membranes incorporating lipophilic organometallic compounds, ${ }^{3,4}$ metalloporphyrins, ${ }^{5-8}$ metallophthalocyanines ${ }^{9-11}$ and Schiff-base metallic complexes ${ }^{12-17}$ have been reported, which have demonstrated potentiometric anion selectivity sequences that deviate from the Hofmeister pattern. These deviations result from a direct interaction between the central metal of the membrane-active components and the analytical anion and steric effect associated with the structure of the ligand. Because iodine is an indispensable microelement to humans, the determination of iodide ion is very important, especially in environment, medicine and food samples. Besides an electrode based on a pressed mixture of $\mathrm{AgI}$ and $\mathrm{Ag}_{2} \mathrm{~S}$ being commercially applied to determine $\mathrm{I}^{-}$, several iodine ionselective electrodes based on a variety of ion carriers have also been reported in the literature. ${ }^{12,13,18-20}$ However, most of these electrodes have one, two or, in some cases, all of the following problems: a) narrow linear ranges, b) high detection limit, c) long response time, d) instability and/or e) serious interfering effect of such anions as $\mathrm{ClO}_{4}^{-}, \mathrm{S}^{2-}, \mathrm{CN}^{-}, \mathrm{Cl}^{-}$and $\mathrm{Br}^{-}$. In the present work, Schiff-base complexes of $\mathrm{Co}(\mathrm{II}), \mathrm{Ni}(\mathrm{II}), \mathrm{Cu}(\mathrm{II})$ (Fig. 1) were synthesized in our laboratory to prepare highly

$\dagger$ To whom correspondence should be addressed.

E-mail: yuanruo@swnu.edu.cn selective iodide electrodes. An electrode containing Co(II)BDMABG with 2-nitrophenyloctylether (o-NPOE) as a plasticizer demonstrated a highly selective and sensitive response to iodide with a substantially improved performance, such as a long lifetime, wide potentiometric response range, low detection limit and small interference from other anionic species.

\section{Experimental}

\section{Apparatus}

All potentiometric and $\mathrm{pH}$ measurements were made with a pH meter (MP 230, Mettler-Toledo, Switzerland) and a digital ion analyzer (Model pHS-3C, Dazhong Instruments, Shanghai, China). Synthesized organometallic complexes were characterized by elemental analysis with a NHC Elemental Analyzer (D-6450, Heracus, Germany). The results are summarized in Table 1. UV-visible absorption spectra were obtained on a UV/Vis spectrophotometer (Lambda 17, PerkinElmer, USA). The A.C. impedance of the electrode membrane was recorded with an impedance measurement unit (IM6e, ZAHNER elektrik, Germany) equipped with THALES software 6.88 .

\section{Reagents and materials}

$N, N^{\prime}$-Bis-(dimethylaminobenzaldehyde)-glycine cobalt(II) [Co(II)-BDMABG], $\quad N, N^{\prime}$-bis-(dimethylaminobenzaldehyde)glycine nickel(II) [Ni(II)-BDMABG] and $N, N^{\prime}$-bis(dimethylaminobenzaldehyde)-glycine copper(II) $[\mathrm{Cu}(\mathrm{II})$ BDMABG] were synthesized by a modification of the reported procedures, as described in the literature. ${ }^{21} \quad N, N^{\prime}$-Bis(dimethylaminobenzaldehyde)-glycine-iodine cobalt(III) [Co(III)-BDMABGI] was synthesized by a modification of the reported procedures, as described in the literature. ${ }^{22}$ The 2nitrophenyloctylether $(o-\mathrm{NPOE})$ was synthesized as described 
Table 1 Elemental analysis of the carriers

\begin{tabular}{llcrc}
\hline \multirow{2}{*}{ Carrier } & & \multicolumn{3}{c}{ Elemental analysis, \% ${ }^{\mathrm{a}}$} \\
\cline { 3 - 5 } & & $\mathrm{C}$ & $\mathrm{H}$ & $\mathrm{N}$ \\
\hline $\mathrm{Co}$ (II)-BDMABG & $\mathrm{C}_{22} \mathrm{H}_{26} \mathrm{~N}_{4} \mathrm{O}_{4} \mathrm{Co}$ & $56.25(56.30)$ & $5.59(5.54)$ & $11.91(11.94)$ \\
$\mathrm{Ni}(\mathrm{II})-\mathrm{BDMABG}$ & $\mathrm{C}_{22} \mathrm{H}_{26} \mathrm{~N}_{4} \mathrm{O}_{4} \mathrm{Ni}$ & $56.39(56.33)$ & $5.50(5.55)$ & $11.92(11.95)$ \\
$\mathrm{Cu}(\mathrm{II})-\mathrm{BDMABG}$ & $\mathrm{C}_{22} \mathrm{H}_{26} \mathrm{~N}_{4} \mathrm{O}_{4} \mathrm{Cu}$ & $55.68(55.74)$ & $5.54(5.49)$ & $11.90(11.82)$ \\
$\mathrm{Co}(\mathrm{III})-\mathrm{BDMABGI}$ & $\mathrm{C}_{22} \mathrm{H}_{26} \mathrm{~N}_{4} \mathrm{O}_{4} \mathrm{ICo}$ & $44.25(44.31)$ & $4.40(4.36)$ & $9.46(9.40)$ \\
\hline
\end{tabular}

a. Calculated values are given in parentheses.

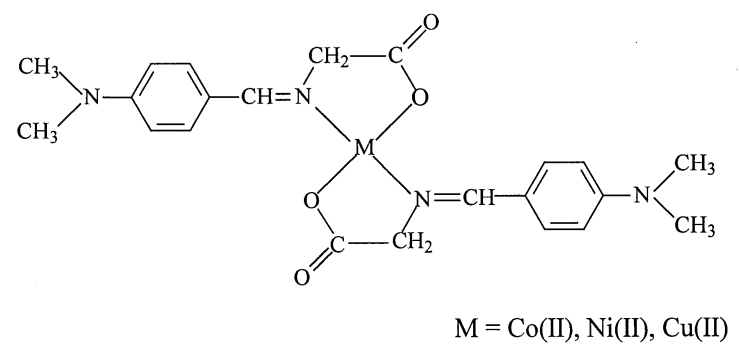

Fig. 1 Structures of $N, N^{\prime}$-bis-(dimethylaminobenzaldehyde)glycine metallic complexes.

by Horning. ${ }^{23}$ All other reagents were purchased from Shanghai chemicals (Shanghai, China) and used without further purification. All of the chemicals used were of analyticalreagent grade. All aqueous solutions were prepared with deionized distilled water.

\section{Sensor construction}

The membrane composition was optimized by using an orthogonal experiment design with the electrode linear response range for iodide ion as the object function for optimization. The optimized result was $3.0 \mathrm{wt} \%$ ionophore, $67.2 \mathrm{wt} \%$ membrane solvent $o$-NPOE and $29.8 \mathrm{wt} \% \mathrm{PVC}$. The PVC membrane electrodes were fabricated from various carriers and assembled according to Thomas and his co-workers. ${ }^{24}$ A solution of 0.1 mol $\mathrm{L}^{-1}$ potassium chloride was used as the internal filling solution and a saturated calomel electrode was used as the reference electrode. The electrode cells for potential measurements were of the following cell assemblies:

$\mathrm{Hg}-\mathrm{Hg}_{2} \mathrm{Cl}_{2} / \mathrm{KCl}$ (sat) / sample solution / membrane / $0.1 \mathrm{M} \mathrm{KCl}$ / AgCl-Ag.

Determination of the emf response of the electrode in an oxygen-free environment

The fabricated PVC membrane containing various ionophores was dried in vacuo. Before use, the electrodes were conditioned in $0.1 \mathrm{M} \mathrm{KI}$ aqueous solutions, which were deoxygenated by bubbling nitrogen through the solutions for $24 \mathrm{~h}$. The various KI solutions were prepared with deoxygenated buffered solutions, and then $\mathrm{N}_{2}$ was allowed to flow over a freshly prepared KI solution while determining the emf response of the electrodes.

\section{UV absorption spectra and A.C. impedance spectra}

UV absorption spectra of Co(II)-BDMABG chloroform solutions were recorded after shaking them with aqueous $0.1 \mathrm{M}$ $\mathrm{I}^{-}(\mathrm{pH} 2.0)$ and a blank buffer solution for $1 \mathrm{~h}$, respectively.

An A.C. impedance plot of an electrode membrane containing Co(II)-BDMABG was recorded. The electrode cells for an A.C.

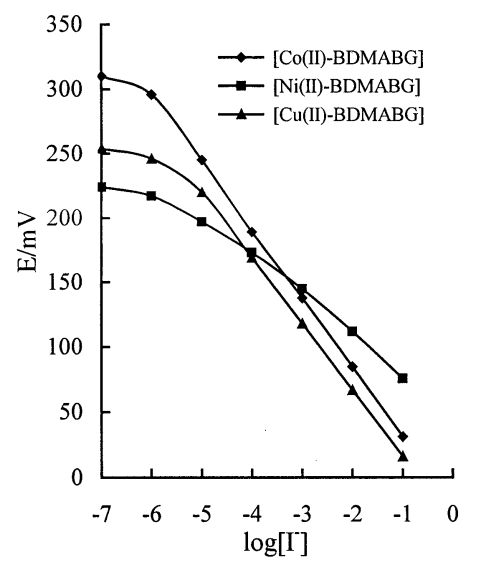

Fig. 2 Potentiometric response characteristics of PVC membranes with various carriers in $0.01 \mathrm{M} \mathrm{H}_{3} \mathrm{PO}_{4}-\mathrm{NaOH}$ solution, $\mathrm{pH}$ 2.0.

impedance determination were composed of an $\mathrm{Ag} / \mathrm{AgCl}$ foil with $0.5 \mathrm{~cm}^{2}$ area as a working electrode, a saturated calomel electrode (SCE) as a reference electrode and a Pt foil with 0.5 $\mathrm{cm}^{2}$ area as a counter electrode, respectively. The frequency region used was $10^{-2}-10^{6} \mathrm{~Hz}$ and A.C. amplitude was $50 \mathrm{mV}$ $\left(20^{\circ} \mathrm{C}\right)$.

\section{Results and Discussion}

Potentiometric response characteristics of electrodes

The potentiometric response characteristics of electrodes containing different carriers are shown in Fig. 2. An electrode incorporating $\mathrm{Co}(\mathrm{II})-\mathrm{BDMABG}$ displayed a near-Nernstian potentiometric response to iodide ion, ranging from $9.0 \times 10^{-7}$ $1.0 \times 10^{-1} \mathrm{M}$ with a detection limit of $6.8 \times 10^{-7} \mathrm{M}$ and a slope of $-53.0 \mathrm{mV} /$ decade in a $\mathrm{pH} 2.0$ of phosphate buffer solution at $20^{\circ} \mathrm{C}$. The response time $\left(t_{95 \%}\right)$ was $10-15 \mathrm{~s}$, implying a fast speed of reversible anion exchange. The standard deviation (SD) of the electrode potential readings over a period of $12 \mathrm{~h}$ in $0.01 \mathrm{M}$ phosphate-buffered solution $(\mathrm{pH} 2.0)$ containing $1.0 \times$ $10^{-3} \mathrm{M}$ KI was $0.68 \mathrm{mV}(n=72)$. The same electrode, dipped alternatively into solutions of $1.0 \times 10^{-2} \mathrm{M}$ and $1.0 \times 10^{-3} \mathrm{M} \mathrm{KI}$, demonstrated a SD of $0.76 \mathrm{mV}$ over $2 \mathrm{~h}(n=12)$. From Fig. 2, one can see that under the same experimental conditions, the electrode based on $\mathrm{Ni}(\mathrm{II})-\mathrm{BDMABG}$ displayed a response to iodide ion ranging from $7.0 \times 10^{-6}$ to $1.0 \times 10^{-1} \mathrm{M}$ with a detection limit of $5.0 \times 10^{-6} \mathrm{M}$ and a slope of $-30.3 \mathrm{mV} /$ decade. An electrode based on $\mathrm{Cu}(\mathrm{II})-\mathrm{BDMABG}$ displayed a response to iodide ion ranging from $5.4 \times 10^{-6}$ to $1.0 \times 10^{-1} \mathrm{M}$ with a detection limit of $2.6 \times 10^{-6} \mathrm{M}$ and a slope of $-51.0 \mathrm{mV} /$ decade. Based on all observations, Co(II)-BDMABG is more preferable than Ni(II)-BDMABG and $\mathrm{Cu}(\mathrm{II})-\mathrm{BDMABG}$. These different 
Table 2 Selectivity coefficient, $\log K_{\mathrm{I}_{-j} \mathrm{j}^{\mathrm{n}}}^{\mathrm{pot}}$, for a Co(II)-BDMABG electrode

\begin{tabular}{lcrrrrrrrrr}
\hline \multirow{2}{*}{ Carrier } & \multicolumn{10}{c}{ Interfering ion } \\
\cline { 2 - 10 } & $\mathrm{I}^{-}$ & $\mathrm{ClO}_{4}^{-}$ & $\mathrm{Sal}^{-}$ & $\mathrm{SCN}^{-}$ & $\mathrm{NO}_{2}^{-}$ & $\mathrm{Br}^{-}$ & $\mathrm{NO}_{3}^{-}$ & $\mathrm{Cl}^{-}$ & $\mathrm{SO}_{3}^{2-}$ & $\mathrm{SO}_{4}^{2-}$ \\
\hline Co(II)-BDMABG & 0 & -1.7 & -2.2 & -2.5 & -2.9 & -3.1 & -3.7 & -3.9 & -4.1 & -4.3 \\
HTOAI $^{\mathrm{a}}$ & 0 & 1.9 & - & 0.5 & -2.8 & -2.0 & -1.4 & -3.1 & - & -4.2 \\
\hline
\end{tabular}

a. Cited from Ref. 12.

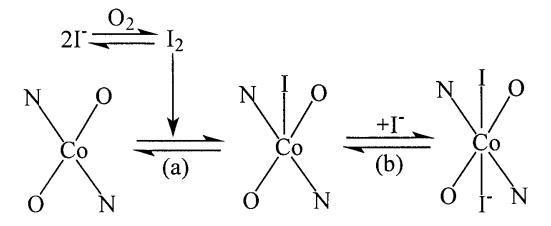

(a) Conditioning

(b) Potential response

Fig. 3 Response mechanism of the electrode.

potential response characteristics imply that the chemical environment, especially a certain substituent, has an important influence on the performance of the electrodes. The electrode incorporating $\mathrm{Co}(\mathrm{II})-\mathrm{BDMABG}$ could be used continually for more than two months, and did not show any detectable loss of its performance characteristics.

\section{Selectivity}

The relative response for the primary anion over other anions presented in solution is an important characteristic of an anionelectrode, which is usually expressed in terms of the potentiometric selectivity coefficients, $\log K_{\Gamma_{j} j^{\mathrm{n}} \text {. }}^{\mathrm{pot}}$ The selectivity coefficients, $\log K_{\Gamma, j^{\mathrm{n}}}^{\mathrm{pot}}$, of an electrode incorporating $\mathrm{Co}(\mathrm{II})$ BDMABG toward different anions, $\mathrm{j}^{\mathrm{n}-}$, were determined by a separate solution method. ${ }^{25}$ The results of an electrode based on a Co(II)-BDMABG electrode are presented in Table 2. It exhibited an anti-Hofmeister selectivity sequence of anion in the following order: $\mathrm{I}^{-}>\mathrm{ClO}_{4}^{-}>\mathrm{Sal}^{-}>\mathrm{SCN}^{-}>\mathrm{NO}_{2}^{-}>\mathrm{Br}^{-}>\mathrm{NO}_{3}{ }^{-}$ $>\mathrm{Cl}^{-}>\mathrm{SO}_{3}{ }^{2-}>\mathrm{SO}_{4}{ }^{2-}$. It was compared with that of an electrode containing a quaternary ammonium salt, hexadecyltrioctylammonium iodide (HTOAI). ${ }^{12}$

\section{Mechanism to iodide response}

Some PVC membrane electrodes containing lipophilic organometallic compounds as anion ionophores displayed an anti-Hofmeister selectivity sequence; the response characteristics were mainly controlled by a special interaction between organometallic compounds and anions, rather than by the lipophilicity of anions or simple opposite-charge interactions with anions. A [Co(II)-BDMABG]-based electrode had a high potentiometric selectivity for $\mathrm{I}^{-}$, mainly owing to the unique interaction between cobalt(II) complexes and iodide ion in an acid solution. In low-pH aqueous solutions, iodide ion can be oxidized to iodine by oxygen. ${ }^{26}$ The reaction of a cobalt(II) complex with iodide was accompanied by electron transfer between the central cobalt and iodine in iodide complexes, which could be described as $\mathrm{Co}^{3+\ldots} \mathrm{I}^{-} .27$ The following reactions took place:

$$
\begin{aligned}
& 4 \mathrm{I}^{-}+4 \mathrm{H}^{+}+\mathrm{O}_{2} \rightleftharpoons 2 \mathrm{I}_{2}+2 \mathrm{H}_{2} \mathrm{O} \\
& \mathrm{I}_{2}+2[\mathrm{Co}(\mathrm{II})-\mathrm{BDMABG}] \rightleftharpoons 2[\mathrm{Co}(\mathrm{III})-\mathrm{BDMABGI}]
\end{aligned}
$$

The interaction between the central $\mathrm{Co}$ (III) atom in complex

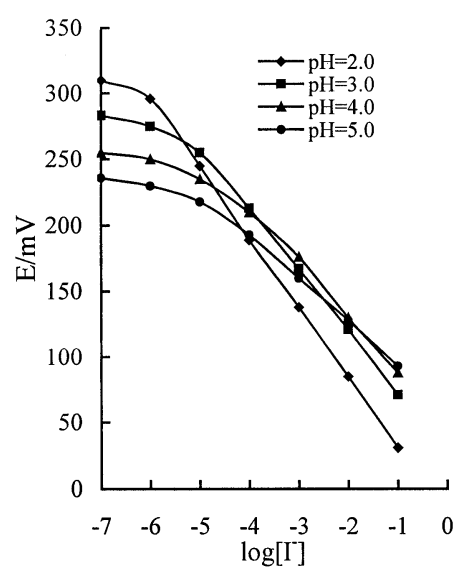

Fig. $4 \mathrm{pH}$ effect on the potentiometric response characteristics of an electrode incorporating $\mathrm{Co}(\mathrm{II})-\mathrm{BDMABG}$ carrier in a $0.01 \mathrm{M}$ $\mathrm{H}_{3} \mathrm{PO}_{4}-\mathrm{NaOH}$ solution.

and $\mathrm{I}^{-}$take place in the axial direction (Fig. 3).

Different buffers, $0.01 \mathrm{M} \mathrm{H}_{3} \mathrm{PO}_{4}$ solutions adjusted with $\mathrm{NaOH}$ at $\mathrm{pH} 2.0,3.0,4.0,5.0$, were used to study the effect of the $\mathrm{pH}$ on the response of electrodes doped with $\mathrm{Co}(\mathrm{II})$ BDMABG in order to be iodide-sensitive. Figure 4 shows the results obtained when the electrode was immersed into buffer solutions with different $\mathrm{pH}$ values. The linear response range and the slope deteriorated with increasing solution $\mathrm{pH}$. From Fig. 5, one can see that under the same experimental conditions as in Fig. 2, the potentiometric response characteristics of the electrode incorporating $\mathrm{Co}(\mathrm{II})-\mathrm{BDMABG}$ displayed a response to iodide ion only ranging from $3.6 \times 10^{-6}$ to $1.0 \times 10^{-1} \mathrm{M}$ with a detection limit of $1.4 \times 10^{-6} \mathrm{M}$ and a slope of $-43.0 \mathrm{mV} /$ decade in an $\mathrm{O}_{2}$-free environment, whereas the potentiometric response characteristics of electrodes incorporating Ni(II)-BDMABG and $\mathrm{Cu}$ (II)-BDMABG in an $\mathrm{O}_{2}$-free environment was nearly the same as that of the electrode exposed to air. By comparing Fig. 4 and Fig. 6, one can see that the effect of oxygen on the performance of the electrode containing $\mathrm{Co}$ (II)-BDMABG in solutions of $\mathrm{pH} 2.0$ was more significant than in solutions of $\mathrm{pH}$ 3.0, 4.0, and 5.0. On the one hand, hydroxide-coordinated central metal might interfere with the response toward iodide. On the other hand, the reaction of iodide with oxygen from air and the formation of iodine would be hindered by the increase of the solution $\mathrm{pH}$. Ascorbic acid should prohibit the oxidation of iodide ion. The potentiometric response characteristics of an electrode containing $\mathrm{Co}(\mathrm{II})-\mathrm{BDMABG}$ displayed a response to iodide ion only, ranging from $4.0 \times 10^{-6}$ to $5.0 \times 10^{-2} \mathrm{M}$ with a detection limit of $2.0 \times 10^{-6} \mathrm{M}$ and a slope of $-47.2 \mathrm{mV} /$ decade with the addition of $0.01 \mathrm{M}$ ascorbic acid. The iodine in solution was reduced by ascorbic acid, and the interaction between the carrier and iodine was weakened.

In order to investigate the interaction mechanism of $\mathrm{Co}(\mathrm{II})$ - 


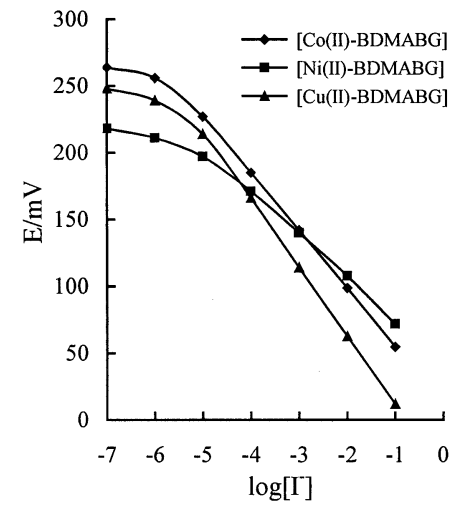

Fig. 5 Potentiometric response characteristics of PVC membranes with various carriers in a deoxygenated $0.01 \mathrm{M} \mathrm{H}_{3} \mathrm{PO}_{4}-\mathrm{NaOH}$ solution, $\mathrm{pH} 2.0$.

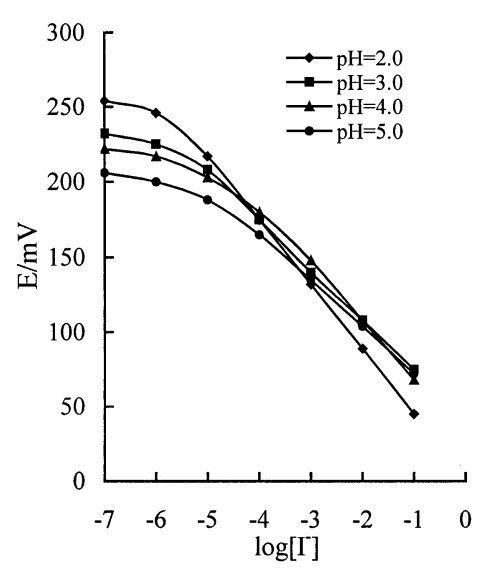

Fig. $6 \mathrm{pH}$ effect on the potentiometric response characteristics of an electrode incorporating a $\operatorname{Co}(\mathrm{II})$-BDMABG carrier in a deoxygenated $0.01 \mathrm{M} \mathrm{H}_{3} \mathrm{PO}_{4}-\mathrm{NaOH}$ solution.

BDMABG with $\mathrm{I}^{-}$, the UV-spectra were measured out. Figure 7 shows the absorption spectra of Schiff-base complexes of Co(II) and $\mathrm{Co}(\mathrm{III})$ in chloroform solution. The spectrum of a chloroform solution of Co(II)-BDMABG treated with 0.1 M KI aqueous solution was different from that of the $\mathrm{Co}$ (II)BDMABG and similar to that of Co(III)-BDMABGI. It was possible to distinguish the interaction between the central metal and iodide ion. The substantial increases in the absorbance of $252 \mathrm{~nm}$ and $294 \mathrm{~nm}$ and a considerable red shift of about $6 \mathrm{~nm}$ (from $\lambda_{\max } 246 \mathrm{~nm}$ to $\lambda_{\max } 252 \mathrm{~nm}$, from $\lambda_{\max } 288 \mathrm{~nm}$ to $\lambda_{\max } 294$ $\mathrm{nm})$ after contact of the carrier solution with the iodidecontaining phase suggested that the absorbing species had increased in size, and axial coordination was thought to take place. Under the same conditions, the effects of anion $\mathrm{I}^{-}$on the spectrum of other ionophores, such as Ni(II)-BDMABG and $\mathrm{Cu}(\mathrm{II})-\mathrm{BDMABG}$, were investigated, and no detectable changes in the UV-spectra were noted.

\section{A.C. impedance of the electrode}

The A.C. impedance spectra of a membrane incorporating $\mathrm{Co}$ (II)-BDMABG conditioned in a pH $2.0 \mathrm{H}_{3} \mathrm{PO}_{4}-\mathrm{NaOH}$ buffer solution containing different concentrations of $\mathrm{I}^{-}$were recorded. As can be seen in Fig. 8, a perfect semicircle bulk impedance at a high-frequency region and a Warburg impedance at a lowfrequency region were observed. The bulk resistance decreased

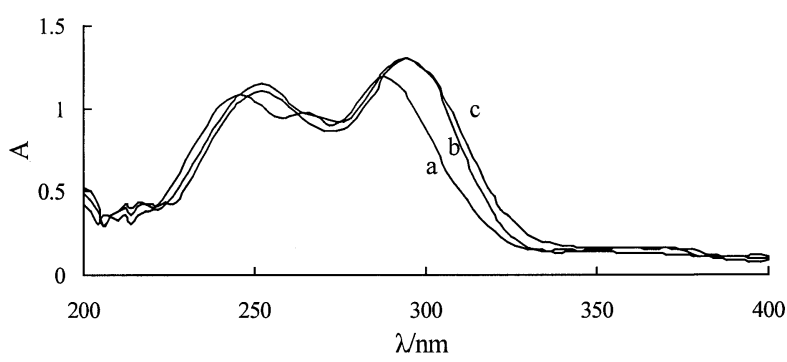

Fig. 7 UV absorption spectra of a chloroform solution of Co(II)BDMABG (a), Co(II)-BDMABG treated with $0.1 \mathrm{M} \mathrm{KI}$ (b), and Co(III)-BDMABGI (c).

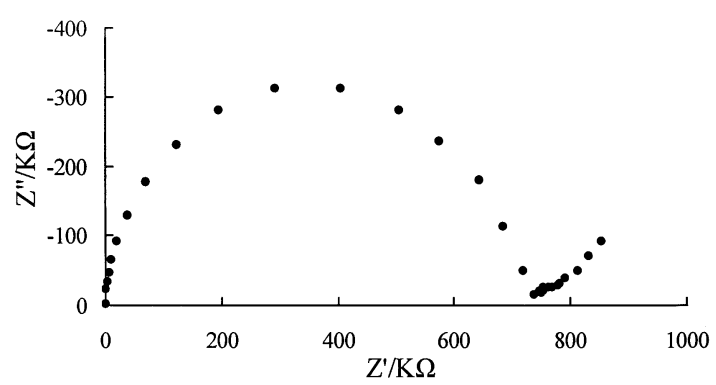

Fig. 8 Impedance plots of a PVC membrane doped with $\mathrm{Co}(\mathrm{II})$ BDMABG.

with increasing the concentration of KI: $8.72 \times 10^{2} \mathrm{k} \Omega$ in $10^{-6}$ $\mathrm{M}, 7.37 \times 10^{2} \mathrm{k} \Omega$ in $10^{-4} \mathrm{M}, 5.84 \times 10^{2} \mathrm{k} \Omega$ in $10^{-2} \mathrm{M}$. It was evident that $\mathrm{Co}(\mathrm{II})-\mathrm{BDMABG}$ could dominate the iodide ion across the membrane, and that the transfer process is diffusion controlled.

\section{Preliminary applications}

To demonstrate the applications of a PVC membrane iodideselective electrode, an electrode incorporating $\mathrm{Co}(\mathrm{II})$ BDMABG was applied to determine the content of $\mathrm{I}^{-}$in Jialin River and Spring in Jinyun Mountains. A $25 \mathrm{ml}$ of sample water was adjusted to $\mathrm{pH} 2.0$ with $0.01 \mathrm{M} \mathrm{H}_{3} \mathrm{PO}_{4}-\mathrm{NaOH}$ buffer. The sample solution obtained above was determined by a potentiometric method. The result obtained indicates that a [Co(II)-BDMABG]-based electrode can be applied to the determination of iodide in actual samples with satisfactory results, as compared with catalytic colorimetry ${ }^{28}$ (see Table 3 ).

In this paper, we have described a new highly iodide-selective electrode based on Co(II)-BDMABG. This electrode is very easy to prepare, has high selectivity and sensitivity, a wide range, a fast response time, fair stability and reproducibility, and a low detection limit. The electrode could be applied to determine the content of $\mathrm{I}^{-}$in actual samples.

\section{Acknowledgements}

Support of this work by the National Natural Science Foundation of China (29705001), the Chinese Education Ministry Foundation for excellent young teacher and the Natural Science Foundation of Chongqing City, China is gratefully acknowledged. 
Table 3 Determination of iodide in Jialin River and Spring in Jinyun Mountains

\begin{tabular}{lcc}
\hline \multicolumn{1}{c}{ Method } & Iodide in Jialin River & $\begin{array}{c}\text { Iodide in Spring in } \\
\text { Jinyun Mountains }\end{array}$ \\
\hline Electrode $^{\mathrm{a}}$ & $4.50 \times 10^{-6} \mathrm{M}$ & $7.11 \times 10^{-7} \mathrm{M}$ \\
Catalytic colorimetry $^{-7}$ & $4.42 \times 10^{-6} \mathrm{M}$ & $7.02 \times 10^{-7} \mathrm{M}$ \\
\hline
\end{tabular}

a. Mean of five determinations.

\section{References}

1. K. Sollner and G. M. Shean, J. Am. Chem. Soc., 1964, 86, 1901.

2. D. M. Pranitis, M. Telting-Diaz, and M. E. Meyerhoff, Crit. Rev. Anal. Chem., 1992, 23, 163.

3. H. Hisamoto, D. Siswanta, H. Nishihara, and K. Suzuki, Anal. Chim. Acta, 1995, 304, 171.

4. Z. Q. Li, R. Yuan, and R. Q. Yu, Talanta, 1998, 46, 943.

5. E. Malinowska and M. E. Meyerhoff, Anal. Chim. Acta, 1995, 300, 33.

6. M. Shamsipur, G. Khayation, and S. Tangestaninejad, Electroanalysis, 1999, 11, 1340.

7. Z. Z. Li, X. B. Zhang, and R. Q. Yu, Anal. Sci., 2002, 18, 423.

8. S. Shahrokhian, A. Hamzehloei, and M. Bagherzadeh, Anal. Chem., 2002, 74, 3312.

9. J. Z. Li, R. Yuan, and R. Q. Yu, Analyst, 1994, 119, 1363.

10. M. K. Amini, S. Shahrokhian, and S. Tangestaninejad, Anal. Chim. Acta, 1999, 402, 137.

11. S. Shahrokhian, Anal. Chem., 2001, 73, 5972.

12. R. Yuan, Y. Q. Chai, and R. Q. Yu, Anal. Chem., 1993, 65,
2572.

13. R. Yuan, Y. Q. Song, and Y. Q. Chai, Talanta, 1999, 48, 649.

14. S. Shahrokhian, M. K. Amini, R. Kia, and S. Tangestaninejad, Anal. Chem., 2000, 72, 956.

15. Y. Q. Chai, W. J. Xu, and R. Yuan, Acta Chim. Sinica (in Chinese), 2002, 60, 2192.

16. R. Yuan, X. L. Wang, and Y. Q. Chai, Electrochem. Commun., 2003, 5, 717.

17. Z. Y. Sun, R. Yuan, Y. Q. Chai, and L. Xu, Anal. Bioanal. Chem., 2004, 378, 490.

18. S. Daunert and L. G. Bachas, Anal. Chem., 1989, 61, 499.

19. V. J. Wotring, D. M. Johnson, and L. G. Bachas, Anal. Chem., 1990, 62, 1506.

20. Z. Q. Li, R. Yuan, M. Ying, Y. Q. Song, and R. Q. Yu, Anal. Lett., 1997, 30, 1455.

21. Z. Wang, Z. S. Wu, Z. H. Yan, Z. F. Le, and X. D. Zhu, J. Central Chin. Normal Univ., 1995, 29, 197.

22. L. G. Marzilli, P. A. Marzilli, and J. Halpern, J. Am. Chem. Soc., 1971, 93, 1374.

23. E. C. Horning, "Organic Synthesis, Coll", 1955, Vol. III, Wiley, New York, 140.

24. A. Craggs, G. J. Moody, and J. D. R. Thomas, J. Chem. Educ., 1974, 51, 541.

25. R. P. Buck and E. Lindner, Pure Appl. Chem., 1994, 66, 2527.

26. R. B. Heslop and K. Jones, "Inorganic Chemistry", 1976 Elsevier, New York.

27. J. H. Burness, J. G. Dillard, and L. T. Taylor, J. Am. Chem. Soc., 1975, 97, 6080 .

28. L. Yu, "Standard of Analytical Approach on Water Quality", 2003, China Environmental Science Press, Beijing, 320. 